\title{
Acute myocardial infarction (AMI) in context with the paradigm - month of birth and longevity
}

\author{
Elyiahu Stoupel ${ }^{1,2^{*}}$, Abdonas Tamoshiunas $^{3}$, Richardas Radishauskas ${ }^{3}$, Gailute Bernotiene $^{3}$, \\ Evgeny Abramson ${ }^{4}$, Peter Israelevich ${ }^{5}$
}

${ }^{1}$ Division of Cardiology, Rabin Medical Center, Petah Tiqwa, Israel;

${ }^{2}$ Sackler Faculty of Medicine, Tel Aviv University, Tel Aviv, Israel; ${ }^{*}$ Corresponding Author: stoupel@inter.net.11

${ }^{3}$ Institute of Cardiology, Lithuanian University of Medical Sciences, Kaunas, Lithuania;

${ }^{4}$ Managing Information Center, Rabin Medical Center, Petah Tiqwa, Israel;

${ }^{5}$ Department of Geophysics \& Planetary Science, Tel Aviv University, Tel Aviv, Israel.

Received 9 September 2011; revised 4 November 2011; accepted 16 November 2011.

\section{ABSTRACT}

Time and environmental physical activity are involved in timing of many medical events. In a recent study published by the National Academy of Science, USA it was shown that month of birth is related to longevity. The aim of this study was to check the month of birth distribution in a great group of AMI patients of both gender, one of the great killers in the developed countries, to check the mentioned paradigm of month of birth and longevity. Methods \& Patients: Patients admitted to Cardiology Departments of a tertiary University Hospital in Kaunas, Lithuania with AMI at years 1990-2010 (n-22047) were studied. Month of birth of these patients, total and both gender were checked. Monthly, quarterly and trimester comparison were done. Statistical differences established using t-Student test and distribution by percents of the yearly months of birth. Results: It was a significant difference in the month of birth of the studied AMI population. January and first quarter and trimester born patients were more often in the studied AMI patients group. The higher morbidity by Cardiovascular diseases can be a significant ingredient in the structure of population longevity. Possible mechanisms explaining our findings are discussed. Conclusion: In the AMI population people born in January, first quarter or trimester of the year are dominating in both gender groups. The results of this study can be an additional confirmation of the paradigm about links between month of birth and longevity.

Keywords: Acute Myocardial Infarction; Month;
Birth; Men; Women; Solar; Geomagnetic; Cosmic Ray; Activity; Nutrition

\section{INTRODUCTION}

For a long time the yearly circle of the Earths dynamics is divided in 12 parts of $30^{\circ}$ named months. The first calendars are assumed to appear at $4241 \mathrm{BC}$ [1-3].

In the ancient world some figures or animals were connected with time of the year, close to the Zodiac symbols classification. Specific yearly parting were done in Rome by Julius Caesar, Augustus and others, with Gregorian (Vatican), Christian Orthodox and Muslim and Jewish modification in their calendars. A yearly calendar exist in China and a number of Buddhist Cultures connected with some animals.

For a long time the individual human fate and it's specificities were linked with the month of birth, or Zodiac sign (close to monthly separation) at the time of birth, a part of Astrology. Despite wide skepticism by many thinkers about such connection, many periodicals are regularly publishing Astrological data and predictions.

S. Hawking and "black hole" assumption as a physical beginning of time [4], the recent works showing the origin of Cosmic Ray (highest known form of energy in the Universe ) with a close to our Galactic black hole radiation $(2007)[5,6]$ space for time understanding. A special part of knowledge-Chronobiology is studying the time-biology, health interrelationship [7-9].

In the year 2001, the Academy of Science of the USA. published a study in the Annals of the Academy about links between month of birth and longevity (inverse for each Hemisphere) [10].

Cardiovascular disease is one of the big killers in the developed countries (Industrial World) [11-13]. Some inequalities can exist in the monthly number of births 
[14].

The aim of this study was to check if some monthly distribution exist in month of birth in patients suffering Acute Myocardial Infarction (AMI) total and each genders as an additional pretext for the paradigm of month of birth and longevity.

\section{PATIENTS AND METHODS}

23070 patients with AMI, admitted in the cardiology departments of tertiary hospital, Lithuanian University of Medical Sciences clinical base in Kaunas, Lithuania at years 1990-2010 were studied. The AMI diagnosis was made in accord to Guidelines using clinical, electrocardiography, echocardiography and laboratory tests [11-13]. At he beginning of the study it was established that 1023 patients registration data not included month of birth. These patients were excluded from the study and we remained with 22,047 patients, 13,415 male $(60.84 \%)$ and 8632 female (39.16\%). The monthly, quarter and trimester of birth of the AMI patients were compared and statistically significant differences between these time intervals established. Significance of $95 \%$ and higher between the compared parameters was accepted as significant. For comparison with concomitant space physical activity monthly data from centers in the USA, Russia, Finland was used [15-19].

\section{RESULTS}

Table 1 presents the AMI according to their month of birth. We can clearly see the differences of the monthly distribution with bulging beginning of the year. Born in January were the most frequent in total and each gender calculation. The average for male patients was $1117 \pm$ 193.89; median 1107.5, for January 1584. Difference (467) more than two SD $(387,78)$ above the average.
The same for female patients: January born-914. Average for all 12 months $719.3 \pm 78.49$; median-710. Difference between January and average of all 12 month 194.7, more than two SD (157.8) higher as the average.

Figure 1 presents the data separately for each gender. Here also the form of distribution remain as for the total group of patients.

Figure 2 presents the monthly birth distribution for five age groups: up to $55 ; 55-69 ; 70-84$ and 85 and older. We can see that the analogical picture of monthly distribution seen in the previous table and picture 1 is repeated in all age groups.

Born in the first quarter, or trimester were more as in the following four or three parts of the year. $(P<0.0001)$. I-2148.667 \pm 305.16; II-1891.667 \pm 108.007 ; III-1739.33 \pm 70.87 ; IV-1569.33 \pm 71.009 average monthly by quarter of the year and I-2084.75 \pm 280.04 ; II- 1824.25 \pm 128.08 ; III-1602.75 \pm 88.4 -by trimester.

Table 1. Monthly births of AMI patients, total and in 4 age groups Kaunas, Lithuania, 1990-2010.

\begin{tabular}{ccccrrrr}
\hline Month of Birth Up to 55 & $55-69$ & $70-84$ & 85 and more & Total & Percent \\
\hline January & 465 & 1141 & 764 & 128 & 2498 & 11,3 \\
February & 401 & 819 & 602 & 112 & 1934 & 8,8 \\
March & 425 & 851 & 639 & 99 & 2014 & 9,1 \\
April & 427 & 789 & 580 & 97 & 1893 & 8,6 \\
May & 439 & 884 & 568 & 108 & 1999 & 9,1 \\
June & 405 & 796 & 500 & 82 & 1783 & 8,1 \\
July & 390 & 792 & 554 & 85 & 1821 & 8,3 \\
August & 376 & 764 & 483 & 71 & 1694 & 7,7 \\
September & 356 & 721 & 553 & 73 & 1703 & 7,7 \\
October & 310 & 694 & 496 & 101 & 1601 & 7,3 \\
November & 304 & 615 & 495 & 74 & 1488 & 6,7 \\
December & 306 & 664 & 552 & 97 & 1619 & 7,3 \\
Total & 4604 & 9530 & 6786 & 1127 & 22047 & 100,0 \\
\hline
\end{tabular}

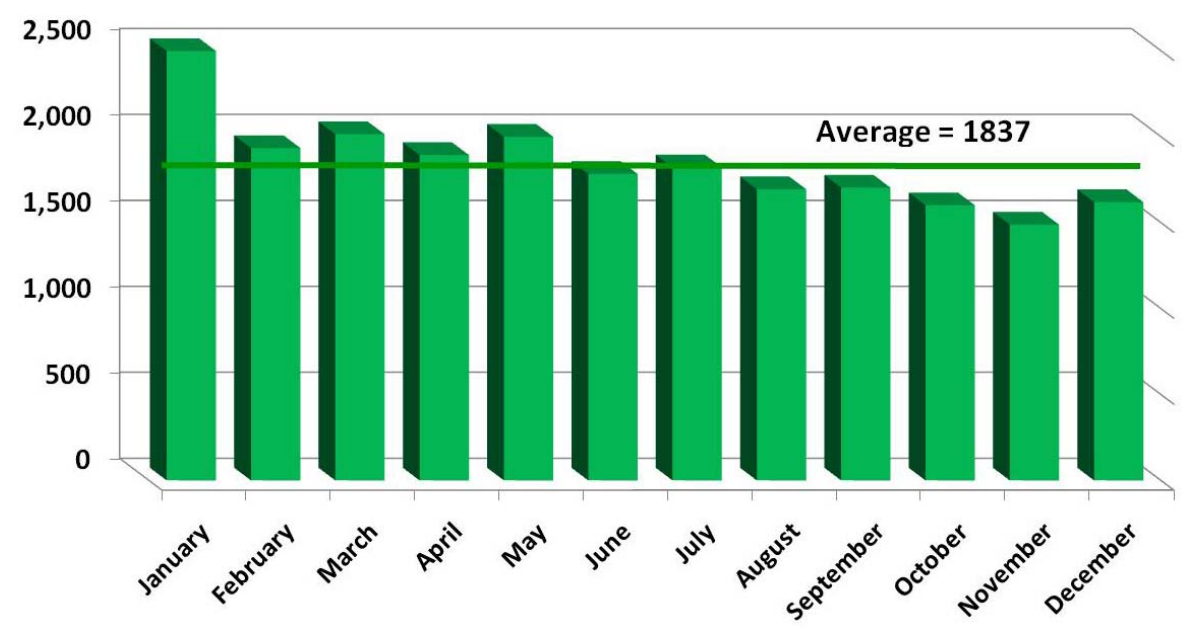

Figure 1. Monthly births of AMI patients (n-22047), Kaunas, Lithuania, 1990-2010. 


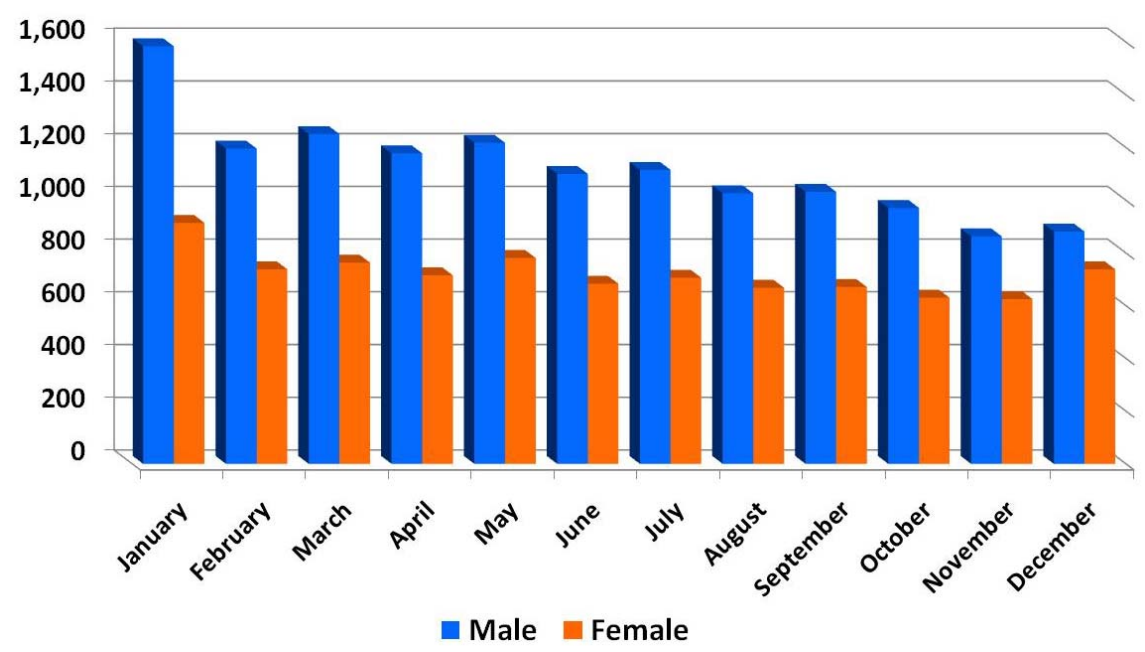

Figure 2. Monthly births of AMI patients both gender (n-22047), Kaunas, Lithuania, 1990-2010.

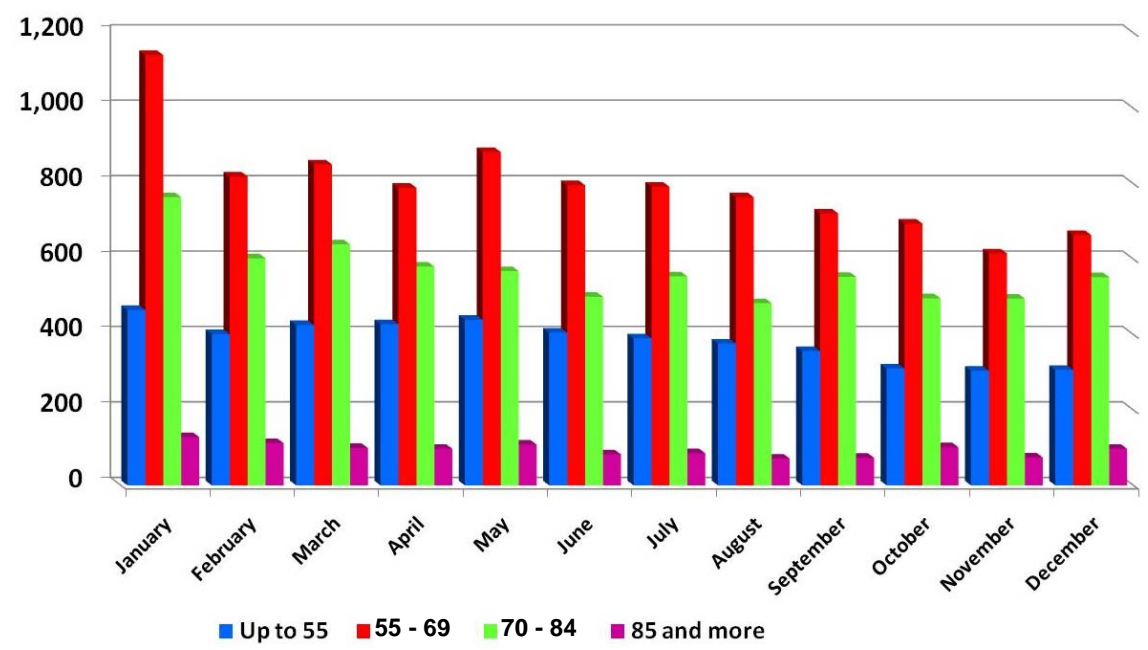

Figure 3. Monthly births of AMI patients (n-22047) in four age groups, Kaunas, Lithunia, 1990-2010.

\section{DISCUSSION}

This is our second attempt to check the monthly birth distribution of patients with acute cardiac events. The first was made on Israeli patients undergoing Percutaneous Coronary Intervention (PCI) for AMI. The study had some limitations:

Until 1950 people arriving to Israel (Palestine until 1948) were registered as born on January 1st. Of our 4732 patients 1154 were excluded from the study as born at January 1st. This was replaced by the average of births on January 2 - 31. Principally the result was similar-born in the first quarter-trimester were more, with special prominence in March [20].

In this study, in different geographic location, but in the Northern hemisphere, we get similar results.

What can be the explanation of the results?
1) It's assumed that predisposition to cardiovascular disease is in one quarter related to genetic factors [21,22], one quarter to factors affecting the fetus at pregnancy and a half-on environmental and day-to-day risk factors linked with lifestyle, working conditions, stress, nutrition [23], accompanying pathologies (Lipid profile, Diabetes mellitus, Renal failure, Hypothyroidism, etc.) [23]. Newborn weight is also connected with environmental physical conditions at the time of conception. So, birth weight was inverse correlated with Carotid artery intima thickness in middle age British men and woman [24].

2) Newborn weight and length are also connected with environmental physical conditions at the time of conception $[24,25]$ are also signs predicting obesity, hypertension and coronary problems in the future and serving 
as risk factors for coronary artery disease in middle age [25].

3) Such physical factors like Time, Solar, Geomagnetic, Cosmic Ray (Neutron) activity are connected with timing of distribution such pathologies like Down Syndrome [26], Congenital Heart Disease [27,28] some forms of congenital failures [29], Cystic fibrosis [30] etc.

4) Solar and Geomagnetic fields are inverse related and serving natural shields against Cosmic Ray (highest known energies) (Neutron activity at the Earth surface in $\mathrm{imp} / \mathrm{min}$ counted) damaging effects on our Planet, but at very high levels SA and GMA are also connected with many human pathologies [30-35].

5) In a study about monthly number of newborns (n286.963) in the same as this study area it was not found significant relationship between month of birth and newborns number, that would explain major shifts in the population according to month of birth and possibility to be affected by a popular disease [36]. No significant relationship in the number of monthly newborns and yearly months $1-12$ was found $(r=-0.0039, p=0.7$, for male, $\mathrm{n}=148089 ; \mathrm{r}=0.03997, \mathrm{p}=0.699$ for female, $\mathrm{n}=$ 138,830; 96 months data).

6) It's shown that Cosmic Ray activity is inverse related to the SA 11-year cycle, but, relatively, not strong variation from month to month [34,36,37].

The sun itself-a source of wave and corpuscular effects on the Earth is significantly changing monthly, and not only yearly. The distance of the Sun is maximal at July 4, minimal at January 3rd. Difference more than $5,000,000 \mathrm{~km}$. Space corpuscular activity can change human enzymes activity-a key mechanism in many bioeffective structure synthesis in human body, including mechanisms involved in Atherothrombosis risk and dynamics [38-40].

7) In addition to the reported in PNAS data about month of birth (10) and longevity opposite results in the two hemispheres of our Planet, it was published by a group of experimental and laboratory scientists that similar observations are made in rats $[41,42]$.

Their findings the authors connect with differences in Melatonin synthesis in rats at different months of the year. Some role of the Geomagnetic and Solar cycle effects are also presumed.

The differences in Solar light intensity and Melatonin production dependence by dark-light interplay can explain the differences in the hemispheres. Some observation are made on Serotonin (Melatonin precursor) cardiovascular effects [43].

But this demands additional studies for explaining the observed month of birth-AMI interrelationship and possible influence on human longevity

\section{CONCLUSIONS}

1) Acute Myocardial Infarction patients are unequal distributed by month of birth. In the Northern Hemisphere they show a significant maximal January, first quarter and trimester prevalence in comparison with following months quarters and trimesters of the year.

This was seen in patients of both gender.

2) The findings in the AMI cohort can be a supporting fragment for the paradigm birth month and longevity.

3) Genetic, social and environmental factors can be involved in the predisposition for coronary atherothrombosis in persons born at the beginning of the year in the Northern Hemisphere.

\section{REFERENCES}

[1] Priestley, J.B. (1964) Man \& time. 1st Edition, Aidus Books Limited, London.

[2] Von Franz, M.-L. (1978) Time rhythm and repose. Thames \& Hudson, 96.

[3] Kenton, W. (1978) Astrology. AVON Books (1974).

[4] Hawking, S.W. (1988) A brief history of time. Bantam Books, Toronto.

[5] Sigl, G. (2001) Ultrahigh energy cosmic rays: Physics and astro-physics at extreme energies. Science, 291, 7379. doi:10.1126/science.291.5501.73

[6] The Pierre Auger Collaboration (2007) Correlation of the highest-energy cosmic rays with nearby extragalactic objects. Science, 318, 938-943.

doi:10.1126/science.1151124

[7] Halberg, F., Cornelissen, G., Chen, C.H., Katinas, C.S., Watanabe, Y. and Otsuka, K. (2000) Chronobiology: The time structures, chronomes gauge, aging, disease risk and the cosmos. Journal of Anti-Aging Medicine, 3, 67-69. doi:10.1089/rej.1.2000.3.67

[8] BeMont, C. (2000) Chronobiology: The rhythm method for overall health Rx.Magazine.

http://magazine.tripod,com/ah-20001218.htm

[9] Stoupel, E., Petrauskiene, J., Gabbay, U., Kalediene, R., Abramson, E. and Sulkes, J. (2001) Circannual rhythmicity in deaths distribution. Acta Medica Lituanica, 6, $37-42$.

[10] Doblhammer, G. and Vaupel, J.W. (2001) Lifespan depends on month of birth. Proceedings of the National Academy of Science, 98, 2934-2939. doi:10.1073/pnas.041431898

[11] Acute Myocardial İnfarction, ICD code I21. International Statistical Classification of Diseases (ICD) and Related Health Problems 10th Revision, Version for 2007, World Health Organization, Chapter IX, Geneva.

[12] Thigesen, K. and Alpert, J.S. (2007) White HD on behalf the ESC/ACCF/AHA/WHF task force universal-definition of myocardial infarction. Circulation, 116, 2634 2653. doi:10.1161/CIRCULATIONAHA.107.187397

[13] Wikipedia (2010) List of causes of death by rate. http://en.wikipedia.org/wiki/.1-5

[14] Realm of Randomness (2007) Are birthdays evenly distributed across the year? World Press. 
[15] SESC Glossary of Solar-Terrestrial Terms (1988, revised 1992) NOAA-USAF, Space Environment Services Center, Boulder.

[16] Solar Indices Bulletin (monthly) NOAA. National Geophysocal Data Center. Boulder, Co, Boulder.

[17] NOAA, SWPC, US AF Preliminary Report and Forecast of Solar Geophysical Data (Weekly) Boulder, Co, Boulder.

[18] Moscow Neutron Monitoring Station. IZMIRAN Institute. Russian Academy of Sciences, Moscow.

[19] Oulu University. Neutron Monitorig Data. Daily, Monthly. Oulu. Finland.

[20] Stoupel, E., Abramson, E., Israelevich, P. and Sulkes, J. (2011) Monthly births distribution in patients with atheroth-rombosis related Acute Coronary Events-(ACS) treated by Percutaneous Coronary Intervention (PCI). Journal of Basic and Clinical Physiology and Pharmacology, 23, 43-47

[21] (2010) Genetic signatures of human exceptional longevity discovered science. http://www.sciencedaily.com/releases/2010/07/10070114 5521.htm

[22] Science News. Longevity tied to genes that preserve tips of chromosomes.

http://www.sciencedaily.com/releases/200911/091/11200 225.htm

[23] American Heart Association (2010) AHA scientific position. Risk factors and coronary artery disease. americanheart. org/presenter. jhtml?ide.

[24] Merlob, P., Raisner, S.H., Shimshoni, M. and Stoupel, E. (1989) Foetal growth in extreme periods of solar activity in the 21-22 solar cycles. Journal of Foetal Medicine, $\mathbf{9}$, 1-2:1-5.

[25] Lawlor, D.A., Davey, S.G., Wincup, P., Wannamethee, G., et al. (2003) Association between offspring birth weight and atherosclerosis in middle aged British men and woman: British regional heart study. Journal of Epidemiology \& Community Health, 57, 462-463. doi:10.1136/jech.57.6.462

[26] Stoupel, E., Frimer, H., Appelman, Z., Ben-Neriah, Z., Dar, H., Fejgin, M.D., Gershoni, B.R., Manor, E., Barkai, G., Halevy, S., Gelman-Kohan, Z., Reish, O., Lev, D., Davidov, B., Goldman, B. and Shohat, M. (2005) Chromosome aberration and environmental physical activity: Down syndrome and solar and cosmic ray activity. Israel, 1990-2000. International Journal of Biometeorology, 26, 1-9. doi:10.1007/s00484-005-0274-2

[27] Stoupel, E., Birk, E., Kogan, A., Klinger, G., Abramson, E., Israelevich, P., Sulkes, J. and Linder, N. (2009) Congenital heart disease: Correlation with fluctuation in cosmophysical activity Intern. Journal of Cardiology, 135, 207-210

[28] Stoupel, E., Dulskiene, V., Kuciene, R., Abramson, E., Israelevich, P. and Sulkes, J. Congenital heart disease and congenital heart disease and environmental physical activitykaunas data, 1995-2005. Sun and Geosphere, 4, 45-49.

[29] Archer, V.E. (1979) Anencephalus, drinking water, geomagnetism and cosmic radiation. American Journal of Epidemiology, 109, 88-97.
[30] Brackenridge, C.J. and Miller, J.R. (2001) Bimodal month of birth distribution in cystic fibrosis. American Journal of Medical Genetics, 5, 295-301. doi:10.1002/ajmg.1320050312

[31] Stoupel, E. (2008) Atherothrombosis-environmental links. Journal of Basic and Clinical Physiology and Pharmacology, 19, 37-45. doi:10.1515/JBCPP.2008.19.1.37

[32] Stoupel, E., Domarkiene, S., Radishauskas, R., Bernotiene, G., Abramson, E., Israelevich, P. and Sulkes, J. (2004) Links between monthly rates of four subtypes of acute myocardial infarction and their corresponding cosmophysical activity parameters. Journal of Basic and Clinical Physiology and Pharmacology, 15, 175-184. doi:10.1515/JBCPP.2004.15.3-4.175

[33] Stoupel, E., Babayev, E., Mustafa, F., Abramson, E., Israelevich, P. and Sulkes, J. (2007) Acute myocardial infarction occurrence: Environmental links. Medical Science Monitor, 13, 175-179

[34] Stoupel, E., Tamoshiunas, A., Radishauskas, R., Bernotiene, G., Abramson, E. and Israelevich, P. (2011) Clin \& exper cardiology neutrons and the plaque: AMI (n-8920) at days of zero GMA/high neutron activity (n-36) and the following days, Kaunas, Lithuania, 2000-2007. Experimental \& Clinical Cardiology, 2, 1-4.

[35] Cornelissen, G., Maggioni, C. and Halberg, F. (2002) Is a birth-dependence of human longevity influenced by halfyearly changes in geomagnetics? Kola Science Center.

[36] Stoupel, E., Kalediene, R., Petrauskiene, J., Gaizhauskiene, A., Israelevicxh, P., Abramson, E. and Sulkes, J. (2006) Monthly number of newborns and environmental physical activity. Medicina, 42, 238-241.

[37] Usoskin, I.G., Alanko-Huotari, K., Kovaltsov, G.A. and Mursula, K. (2005) Heliospheric modulation of cosmic rays: Monthly reconstruction for 1951-2004. Journal of Geophysical Research, 110, A12108. doi:10.1029/2005JA011250.

[38] Wikipedia Sunlight. http://en.wikipedia.org/wiki/Sunlight//

[39] Kirby, A.J. and Hollffelder, F. (2008) Enzymes under the nanoscope. Nature, 456, 45-47. doi:10.1038/456045a

[40] Feelisch, M., Kolb-Bachofen, V., Liu, D., Lundsberg, J.O., Rovedo, L.P., Suschek, C.V. and Weller, R.B. (2010) Is sunlight good for the heart. European Heart Journal, 31, 1041-10

[41] Bartsch, H., Bartsch, Ch., Mecke, D. and Lippert, T.T. (1994) Seasonality-pineal melatonin production in the rat. Possible synchronization by the geomagnetic field. Chronobiology International, 11, 21-26. doi: 10.3109/07420529409057227

[42] Bartsch, H., Kupper, H., Scheurlen, U., Deerberg, F.D., Seebald, E., Dietz, K., Mecke, D., Probst, H., Stehle, T. and Bartsch, Ch. (2010) Effect to a chronic exposure to a GSM-like signal (mobile phone) on survival of female Sprague Dawley rats: Modulatory effects by month of birth and possibly stage of the solar cycle. Neuroendocrinogy Letters, 31, 457-473.

[43] Saxena, P.R., Wallis, D.I., Woulters, W. and Bevan, P. (1990) Cardiovascular pharmacology of 5-hydroxytryptamine. Kluver Academic Publishers, Dordrecht. 